\title{
DESIGNING ONLINE COURSES FOR SCREEN READER USERS
}

\author{
Lorna R. Kearns \\ Barbara A. Frey \\ Gabriel McMorland \\ University of Pittsburgh
}

\begin{abstract}
A review of multiple online courses at one institution was conducted by a skilled screen reader user for the purpose of assessing the extent to which the courses were navigable and understandable to online students using assistive technologies. This paper identifies features of online courses that may present problems for screen reader users and recommends solutions to address those problems. The following two overarching recommendations are suggested and elaborated: (1) just as a roadmap assists drivers in navigating unfamiliar terrain, principles of clarity, consistency, and organization should be applied to the design of online courses to orient students to the virtual learning environment and (2) web pages and course documents should make effective use of metadata (i.e., machine-understandable information about computer-based content) in order for course material to be accurately understood by students using a screen reader.
\end{abstract}

\section{KEYWORDS}

Online Learning, online teaching, universal design of instruction, accessibility

\section{INTRODUCTION}

In higher education, the number of online students has grown from 1.6 million in 2002 to over 6.1 million in 2012 [1]. Considering that $10.8 \%$ of the students in four-year postsecondary institutions had some type of disability in 2008 [2], we can only assume that many of our online students have some type of disability. One of many advantages of online courses is that these students with disabilities are not required to self-identify unless they are requesting an accommodation, such as extended time on an exam or project. As administrators, faculty, and course developers, it is our legal and ethical responsibility to proactively provide our learners with accessible courses.

Despite the growth of online education in the last decade, the virtual classroom is still unfamiliar terrain for many students. Similar to navigating foreign territory in the physical world, students with disabilities often enter a complex environment with numerous sites, navigation paths, and access points. In some cases, there are specific gates through which they must pass in order to gain admission into another area of the course. Thus, seemingly minor navigation barriers can render whole sections of a course inaccessible. Along the journey, there are policies, procedures, and standards of conduct that must be followed. The purpose of this manuscript is to highlight inclusive design strategies for developing online courses based on the experiences and feedback of a skilled screen reader user. With attention to best practices, developers can create courses with clear pathways, obvious landmarks, and time-saving shortcuts.

During the summer of 2012, the authors of this paper collaborated on a comprehensive study to assess the accessibility of multiple online courses at one institution. All the courses were part of a university-wide initiative offering graduate-level, online degree programs in nursing, education, and gerontology. One of the authors of this paper, our disability services quality assurance assistant, is a legally blind screen reader 
user. A screen reader "uses synthetic speech to tell the user (usually someone who is blind) what is on the monitor and to confirm that the key is being pressed when writing" [3, p. 4]. This author provided feedback to instructional technologists and designers who work with faculty to develop their online courses. While he noted accessibility issues for students with all types of disabilities, the primary focus of the summer initiative was to develop accessible courses for students who use screen readers. Through reviews of dozens of online courses, our summer initiative yielded best practices for creating courses with a road map that benefits all students.

As noted by several authors [e.g., 4, 5, 6, 7], our accessible course design practices benefit students beyond the initial target group of visually impaired students. Students with low literacy, low bandwidth, or older operating systems appreciate accessible course design practices. For example, "chunking” information into organized themes with clear headings makes the text easily read and understood by learners. Transcripts and closed captioning make course content more comprehensible for non-traditional students or those who speak English as their second or third language. Transcripts presented in a digital format allow the content to be keyword searchable. Accessible material is also more compatible with multiple web browsers, plus tablet and mobile devices.

For the purposes of this article, accessibility refers to an inclusive design concept in which students with disabilities can perceive, understand, navigate, interact, and contribute to their web-based courses. Closely related to the concept of accessibility is universal design, or "the design of products and environments to be usable by all people, to the greatest extent possible, without the need for adaptation or specialized design" [8, para. 1]. In recent years, we have seen the term universal design broadened from physical environments to include making web environments more accessible to users of all ages and abilities. This proactive universal design approach to the development of online courses reduces the need for accommodations, or the necessary and appropriate modifications to ensure that individuals with disabilities have access to all course materials. In addition to universal design, we borrowed the concept of landmarks from an emerging set of specifications being developed by the Web Accessibility Initiative that aims to make web-based content more accessible [9]. Landmarks provide a way for HTML developers to make screen readers aware of commonly found areas of a web page like banners, navigation bars, and search tools [10].

\section{LITERATURE REVIEW}

Much of the research on accessibility for online learning is rooted in the work on accessible web design. The research also ties the application of universal design principles to the design of instruction. The following sections will identify commonly cited resources from both of these fields, describe the work that has been done on accessibility issues in online learning, and conclude with an overview of screen reader usage, both among the general population and specifically among online learners.

\section{A. Web Accessibility}

The Rehabilitation Act is a federal law enacted in 1973 to prevent discrimination against individuals with disabilities in federally assisted programs, services, and employment. Section 508 [11] of the law was amended in 1998 to specifically address the accessible use of information technology by disabled individuals. In 2000, a set of standards [12] was published to specify criteria with which information systems developed or procured by the federal government must comply. The portion of the standards that applies to web-based applications is frequently cited in the literature as a framework for evaluating the degree of website accessibility [e.g., 13].

The World Wide Web Consortium [14] is an international community of experts who specify standards for developing web content. One of their functional units, the Web Accessibility Initiative [15], publishes the Web Content Accessibility Guidelines (WCAG). These guidelines, now in their second version [16], are frequently used as a guiding framework for designing accessible websites [17, 18].

An initiative of Utah State University's Center for Persons with Disabilities is the Web Accessibility in Mind [19] (WebAIM) program. WebAIM provides training and consultation services as well as resources 
for use in developing accessible websites. These resources include a Section 508 checklist, a WCAG 2.0 checklist, and an automatic accessibility checker for HTML pages [20].

\section{B. Universal Design of Instruction}

The Disabilities, Opportunities, Internetworking, and Technology Center (DO-IT) [21] at the University of Washington promotes the success of disabled persons in postsecondary institutions, especially in regard to the use of information technology. Among the resources published by the center are principles and practices associated with the universal design of instruction (UDI) [22, 23, 24]. Principles of UDI may influence the design of classroom and other learning spaces, instructional delivery methods, weband computer-based instructional resources, assessments of learning, and even personal interactions [22]. A conceptual piece by Scott, Mcguire, and Shaw [25] provides an example of how the principles may be applied to adult education in postsecondary institutional settings.

An area of research which draws on principles of UDI and standards of web accessibility is the accessibility of instructional websites. Most often deployed via a learning management system such as Blackboard [26] or Moodle [27], instructional websites can be used in both face-to-face and online classes as a content repository for instructional materials and platform for communication. Lewis, Yoder, Riley, So, and Yusufali [28] described a project initiated at the University of Texas at Austin in which students evaluated instructional websites for accessibility barriers. Reported barriers included inability to skip repetitive navigational links, missing alternative text for images, poorly labeled form fields, and confusing heading structure. Bradbard and Peters [17] detailed their own attempts to make their instructional websites more accessible. Based on their experiences, they concluded that, while many instructors would identify web accessibility as a worthwhile goal, few have the time or technical expertise to successfully manage the process on their own. Therefore, Bradbard and Peters recommended that universities explore ways to assist faculty in developing and maintaining accessible instructional websites.

Researchers have also studied the extent to which postsecondary institutional websites conform to web accessibility standards. Smith and Lind [29], for example, used a variety of web accessibility checkers to evaluate accessibility conformance of websites of schools of education in order to test a number of hypotheses about accessibility, one of which was that more complex websites would have lower levels of conformance. They found that as complexity of websites increased, levels of accessibility decreased. An early study conducted by Schmetzke [30] used a web accessibility checker to evaluate 219 websites of postsecondary institutions offering distance learning programs and found only $15 \%$ to be free of major accessibility errors.

\section{Accessibility Issues in Online Learning}

Kinash, Crichton, and Kim-Rupnow [31] conducted a literature review on the needs of disabled online students. A prevalent theme among the articles reviewed was the potential for accessible online course materials to benefit all learners, not just those who were disabled. Additionally, a few studies focused on policy and procedures for creating accessible online courses. Burgstahler, Corrigan, and McCarter [32] described a case study on the development and maintenance of accessible distance learning courses at one institution that has been recognized for its accessibility efforts. Recommended best practices included the development and dissemination of policies, procedures, and design guidelines; training and support for all faculty and staff involved in developing online courses; and the establishment of an ongoing evaluation and revision process for online courses.

More recently, Frey and King [33] conducted a survey among institutions of higher education to discover whether a policy for developing accessible online courses existed. Although 99\% of institutions had a disability services policy in place, only $13 \%$ had a specific policy guiding the development of online courses. Despite a consensus that such a policy is a legitimate responsibility of institutions, the majority of institutions did not have a budget for creating accessible course content. As an extension of this work, a template was developed by Frey, Kearns, and King [34] and published by Quality Matters [35] for use by institutions wishing to develop such a policy. 
Principles of UDI have been used as a framework for presenting recommendations for designing accessible online learning. Elias [36] systematically examined one online course according to UDI principles and found relatively few aspects of the course that achieved the goals of UDI. Duranczyk and Higbee [37] described the use of an integrated multicultural instructional design model to inform the development of online courses at one institution. They presented specific examples of how the model guided teaching practices, assessment strategies, and student support services. Burgstahler, the author of several UDI resources [22, 23, 24], created a list of accessibility indicators, used the indicators to increase accessibility of online courses at one institution, and reported on efforts to refine the list based on communications with other institutions [4].

Both WCAG 2.0 [16] and Section 508 [11] have also been used to examine online courses and inform recommendations for accessible course design. Frey and Kearns [18] used the four principles of WCAG 2.0-perceptibility, operability, understandability, and robustness-to propose a quality assurance process for inclusive online course design. Edmonds [13] used the Section 508 standards to present recommendations for designing accessible online courses. He addressed issues involved with the design of so-called first generation materials, HTML pages, as well as second generation materials, such as Adobe and Microsoft Office files.

Because it is important to understand the specific limitations and inherent accessibility barriers unique to each of these second generation applications, several web-based resources have been developed to assist in the creation of such materials. The Center for Assistive Technology and Environmental Access at the Georgia Institute of Technology publishes Guidelines for Accessible Distance Education [38] for second generation course materials developed with Adobe and Microsoft Office applications. Adobe [39] and Microsoft Office [40] also maintain websites devoted to guiding the development of accessible materials created with their software. Resources such as these help people understand the limits of each application, ensuring that content is delivered in a format appropriate to its intended use.

\section{Screen Reader Use}

Lazar, Allen, Kleinman, and Malarkey [41] recruited 100 screen reader users across multiple work and home settings and computer platforms to keep a diary of challenges in screen reader usage. Challenges included confusing page layouts, technical incompatibilities between the screen reader and a web-based plug-in, poorly designed forms, lack of alternative text for images, poorly labeled hyperlinks, inaccessible PDF files, and screen reader crashes. Asakawa [42] wrote an article about her own experiences as a screen reader user starting in 1994. She concluded that, although websites are increasingly being designed for accessibility, it is evident that many do not have a realistic understanding of the overall aim of accessible design. Asakawa's study emphasized the need for including actual screen reader users in the design and development phases of web-based materials.

Borodin, Bigham, Dausch, and Ramakrishnan [43] conducted a study of browsing strategies developed and used by screen reader users. Because screen readers read all text on a web page in a particular order, they have an impact on the speed with which a user can process information on that page. As a result, many screen reader users develop shortcut strategies to browse pages more efficiently. These shortcuts may include jumping from one heading to the next, remembering the order of particular web page elements from one page to the next, or employing keyword searches.

The studies cited above pertain to general screen reader users. Research has also been carried out with online learners who use screen readers. Leporini and Buzzi [44] argued that e-learning environments need to be developed with screen reader users in mind. Muwanguzi and Lin [45] described the experiences of five blind students who had taken online courses. They reported numerous difficulties and challenges, most of which stemmed from not being able to successfully use a screen reader with portions of the course, such as online chats and supplemental PDF and Microsoft PowerPoint files.

Zebehazy [46] used a think-aloud protocol to record the impressions of four students, two who were blind and two who were sighted, as they worked through two lessons in an online course. A pronounced difference between the blind and sighted students was the manner in which they moved through the 
material. The sighted students jumped back and forth far more than the blind students who tended to advance through the content in a more linear fashion. The author's recommendations included placing segments of related information in close proximity, developing text-based explanations of graphics to help blind students create visual images, maintaining format consistency when using text to describe graphics (e.g., always place textual information either before or after a graphical image), and avoiding the use of boldface as the sole means of calling attention to key terms.

\section{E. Research Questions}

Based on our review of the literature and input from the screen reader evaluation of courses, we attempted to answer the following research questions:

1. What features of the examined courses present problems for a screen reader user?

2. What recommendations can be made to address those problems?

\section{RESULTS}

Like any computer user, a screen reader user relies on consistency of screen layout and organization to facilitate navigation of pages belonging to an individual website. Sighted users look for navigation links across the top and along the left side of web pages. Even without visual or spatial reference points, screen reader users employ a similar strategy, expecting consistency from page to page in a website. Online students, both sighted and those using screen readers, look for such consistency across courses. Our screen reader user encountered difficulty when moving from one course to another when navigation menu items were named or ordered differently. For example, some courses used a navigation menu item labeled "Learning Modules" and some used "Lessons" for the same type of content.

Another source of difficulty was the use of locational or other visually-based language in instructions. A screen reader user is not able to glean the same information as a sighted user from sentences such as "To take the quiz, click the link on the left side of the screen," or "Press the blue Submit button when you are finished.” Bolding, italics, and color are often used to convey emphasis to sighted users. Words and phrases highlighted in this fashion were spoken by the screen reading software in the same way as the surrounding text. In other words, they were not emphasized at all by the screen reader.

In order to quickly get a sense of the meaning of a page, our screen reader user employed a strategy whereby he jumped from heading to heading, almost like reading a table of contents. In some of the courses our screen reader user reviewed, heading codes were not used to tag headings. Instead, words and phrases were simply set in a larger or bolded font. Designed in this way, headings are "invisible," rendered by the screen reader as just another phrase in a stream of text. Another jumping strategy our screen reader user employed was to move from one hyperlink to the next. When hyperlinks are labeled with phrases such as "click here" or "download," our screen reader user was unable to decipher the meaning of the hyperlink without reading the surrounding text. When the hyperlink label contained nothing more than a long URL address, additional reading was once again necessary. Some web pages used the same text, such as "rubric," instructions," or "video," for links to different documents.

Tables present a special challenge to screen reader users because screen readers read from top to bottom, left to right, without repeating column and row headings. Thus, large, complicated tables can be extremely difficult to understand. Moreover, complex tables with merged cells can cause the screen reading software to read data out of order. Often, our screen reader user could not make any sense at all of a table.

Some of our courses contained narrated PowerPoint lectures created with lecture capture applications (e.g., Articulate [47], Adobe Captivate [48]). Our screen reader user encountered several problems when listening to such lectures. He found it confusing to listen to the narration without knowing when the slides were advancing. In cases where the creator of the lecture neglected to use slide headings, the table of contents generated by the application contained many missing entries, making it difficult to navigate 
through the lecture. Slides containing charts, graphs, and images often did not include an alternative text tag to explain the meaning of purpose of the image.

Many online courses direct students to external websites to gather information and conduct research. Sometimes, students use these sites to interact with a database or run an animation. As our screen reader user moved through course content, he occasionally encountered websites that were partially or wholly inaccessible to his screen reader, thus making it problematic to complete an activity or assignment. At other times, he had to open or download a supplemental file (e.g., PDF file or Microsoft Word document), only to find it partially or completely inaccessible. When PDF files are created by scanning a printed page, they are not readable by a screen reader unless they are prepared using optical character recognition. These were the common patterns discovered in our accessibility review. They led to the development of the following guidelines that we incorporated into our own quality assurance process.

\section{RECOMMENDATIONS}

Based on the results of this study, we propose two primary sets of guidelines that are supported by research and best practices. First, design the course website to function like a road map that assists students in orienting themselves to the landscape of the course, helping them make optimal use of course landmarks. These observable course enhancements focus on the organization and navigation of course materials. Second, use metadata to create a solid foundation upon which to build course content. This second set of guidelines deals with behind-the-scenes coding. While all users (e.g., mobile technology users) will benefit from the appropriate use of metadata, the resulting changes are not observable to sighted users upon their initial review of the course materials.

\section{A. Provide a Road Map}

To assist students in developing good navigational skills, course sites should be designed using an organizational structure that conveys clear and useful information, optimizes the affordances of the technological environment, and provides, to the greatest extent possible, an accessible student experience. Online courses can present barriers when the design and technology are not meticulously planned to consider the needs of all learners. Screen reader users usually navigate the online world in a low-vision or non-visual, non-spatial manner, and good information design must take this user experience into account.

\section{Web Design}

Online courses should align with basic web design considerations, including high-contrast colors, plain backgrounds, and scalable text for low vision or color blind students. Buttons and links should be large enough to click and balanced with adequate white space. Fonts such as Verdana, Lucida, and Georgia are specifically recommended for reading on a computer screen [49]. Students should have access to all sections of the course at the start of the term, so that unique accessibility challenges can be discovered and addressed before students work too far into the course. While it is our responsibility to proactively design inclusive online courses, it is impossible to address every issue for every student. Within reason, students have the responsibility of checking a few weeks ahead of schedule for barriers to their progress. This advanced access will allow any disability support staff working with the student to reduce delays in providing student accommodations, such as specialized tutoring or document conversion.

\section{Syllabus or Read Me First}

Each course should include a section offering students a clear, comprehensive road map explaining the location and function of all course elements. Some faculty describe this course structure in the syllabus while others use a separate "read me first" document. In either case, students should be able to visit one location to find information clearly describing the navigation elements, accessibility features, and known accessibility challenges as well as information about textbooks, websites, and a list of file formats for all supplemental materials. Instructors should select software and tools that are accessible to all students. For example, VoiceThread [50] may not be accessible to all students. As noted by Zebehazy [46], students 
using screen readers review course materials in a scrolling, linear manner rather than jumping from assignments to reading materials or schedule due dates to grading rubric. Course developers can enhance the readability of their course by grouping all related information together.

\section{Consistent and Predictable Layout}

In cases where individual courses are offered as part of an entire online program, all courses within the program's curriculum should have consistent labels and section names with similar functions whenever possible. For example, the same menu navigation buttons should be used in every nursing or education course. Students become confused when the same module is referred to as a lesson or unit, rather than a module.

Headings are the main navigation landmarks used by screen reader users to discover and revisit content. Headings are most effective when they lead users through all relevant content and allow users to quickly return to important parts of a page. Module or lesson headings (e.g., Objectives, Readings, and Lectures) should have meaningful names and form a consistent, predictable, and uncluttered structure in each page's layout.

Narrated lectures and other media files should be introduced with a short text statement specifying what content they contain; for example, audio only, video and slides, or slides only. This description helps students know they have accessed all the lecture components. If a supplemental website is not fully accessible to students, then the specific activity students are required to perform should be fully accessible. That is, the path to perform the assigned task must meet the WCAG guidelines, even if the other parts of the larger website do not. Any special instructions required to ensure an accessible experience should be included in the overall instructions for the activity.

\section{B. Use Metadata Effectively}

The purpose of metadata, a core concept in fields like library and information sciences, is to assist in the organized storage and retrieval of information as well as with the interoperability of data in different systems. Metadata contains machine-understandable information about computer-based data or other digital resources. In other words, it is data about data [51]. When you hover your mouse over the name of a file on your computer, you see a small box with information about the size of the file, the type of file it is, the author of the file, and the date it was created or modified. This information is part of the metadata associated with that particular file.

In the context of online course design, we find the concept of metadata helpful in guiding our thinking about how effectively a course site may be understood by a student using an assistive device like a screen reader. In other words, we view assistive devices as machines for which our metadata renders our courses more machine-understandable. Metadata is the information design layer that combines with the visual layout to communicate universally relevant information.

\section{Alternative Text}

A common example of metadata is the addition of an alternative text tag to a computer-based image. When you add "alt text" to an image, you provide a short textual description of the image that can only be seen when the user hovers the computer mouse over the image. Alt text tags are important for visuallyimpaired users who cannot see an image. If they use a screen reader, it will announce the alt tag instead of just skipping over the image. A lesson on the Civil War, for example, might include an image of Abraham Lincoln with an alt text tag that conveys the information, "Portrait of Abraham Lincoln." Alt text descriptions can be attached to images, charts, and graphics in HTML, PDF, DOC/DOCX (Microsoft Word), and PPT/PPTX (PowerPoint) file types. These tags should convey all of the information contained in the image that is necessary for students to achieve learning objectives. When students use images as part of an assignment that will be presented to the class, they should be instructed to attach an appropriate alt text tag.

\section{Headings}


Unlike visual users, screen reader users can never take in the entire layout of a page at one time. Instead, screen reader users read through the page content one line of text at a time using the arrow keys, or explore pages using shortcut keys that enable navigation via screen elements, such as headings, links, or buttons. When creating headings on a page of text, whether working in HTML, PDF, or DOC/DOCX file formats, use the supplied heading metadata feature; e.g., use $\mathrm{H} 1$ tags to indicate heading level 1 on an HTML page. When headings are created this way, the screen reader can jump from one heading to the next, thus allowing the student to skim the page using just the headings. Keeping this in mind, headings should have meaningful names and form a consistent, predictable, and uncluttered structure in each page's layout. Headings are the main navigation landmarks used by many screen reader users to discover and revisit content. Headings should both lead users through all relevant content and allow users to quickly return to important parts of a page.

Of course, headings are also used to convey information to visual users. A centered, 20-point, boldface font may signal a title of a page or document. Similarly, a left flush, 12-point, italicized font may indicate a sub-heading of some kind. These informational qualities can be retained for use with a screen reader only by using the appropriate metadata mentioned in the previous paragraph, thus enabling both visual users and screen reader users to perceive the information intended by the author. When the intent is to convey such information, the goal is to ensure universal accessibility. Therefore, using boldface, italics, or color to convey important information without using the appropriate metadata should be avoided. (Attention screen reader users: the previous sentence displayed the word "boldface" in boldface, the word "italics" in italics, and the word "color" in a blue font.)

\section{Hyperlinks}

Screen readers are able to identify hyperlinks so that skimming can be accomplished by jumping from hyperlink to hyperlink listed on a page. Thus, it is important to use meaningful link names that describe the link's function without the context of other on-screen text. Do not use phrases such as "click here" or "download" as link names. For example, to have students access instructions about an essay assignment, it is better to say "before you begin, please download the essay instructions," than "before you begin, please download the essay instructions," or "before you begin, click here to download the essay instructions." In a similar vein, do not use the same link name to refer to two or more different resources. In a lesson that includes both a journal article and video about workplace bullying, do not use the phrase "workplace bullying” for both. Do not use URLs as link names: because a screen reader reads every character of a URL, the true meaning of the link is often obscured. Instead, choose a meaningful name, like "Google" instead of https://www.google.com/, and attach the URL as a hyperlink to the name (e.g., Google).

\section{Tables}

Tables present special challenges to screen readers. The rule of thumb when using tables is to keep them as simple as possible. The default reading order for a screen reader is left to right, top to bottom [49]. For example, a screen reader would read the contents of table 1 as "Group, Presentation Date, Group 1, March 11, Group 2, March 11, Group 3, March 18, Group 4, March 18.”

\begin{tabular}{|l|l|}
\hline Group & Presentation Date \\
\hline Group 1 & March 11 \\
\hline Group 2 & March 11 \\
\hline Group 3 & March 18 \\
\hline Group 4 & March 18 \\
\hline
\end{tabular}

Table 1. Simple table with one header row, four data rows, and two data columns

Keeping a table simple means using only as many rows and columns as are absolutely necessary and avoiding merged data cells such as those contained in table 2. Although the data in this table convey the 
same information to a visual user, a screen reader would read the contents as "Group, Presentation Date, Group 1, March 11, Group 2, Group 3, March 18, Group 4.” Even with this minor change, the screen reader version becomes less understandable.

The tables shown in these examples are data tables. Web developers working in HTML sometimes also use tables to accomplish page layout goals. That is, they position design elements within tables in order to display them in a particular format in a web browser. Although some accessibility guidelines recommend avoiding the use of such layout tables, the newer screen readers handle them well, as long as these tables do not use complex formatting, like merged cells [49]. The best practice when using tables for layout in HTML would be to check the reading order with a screen reader after you create the table.

\begin{tabular}{|l|l|}
\hline Group & Presentation Date \\
\hline Group 1 & March 11 \\
\hline Group 2 & March 18 \\
\hline Group 3 & \\
\hline Group 4 & \\
\hline
\end{tabular}

Table 2. Table with merged data cells in right column

Because it is not always possible to avoid creating complex tables, there are ways to make such tables more screen reader friendly. In HTML, for example, the table header tag, TH, in combination with the SCOPE tag, can be used to associate the contents of each cell with the appropriate row and column heading so that the screen reader announces a heading for every data cell value it reads $[49,19]$. To avoid overwhelming verbosity and clutter, these features should be used judiciously and always tested with a screen reader to make sure the intended outcome is achieved. CAPTION and SUMMARY tags are also available when making tables $[49,19]$. The CAPTION tag can be used to provide a short title for a table, such as "Group Presentation Dates," while a SUMMARY tag might contain the text "Group Presentations will be held on March 11 and March 18."

\section{Supplemental Files}

Online courses often contain hyperlinks to non-HTML supplemental documents. Applications commonly used to create these "second generation" [13] files are Microsoft Office [40, 52] for word processing, presentation, and spreadsheet files and Adobe Acrobat [39] for PDF files. Each of these applications has features that facilitate the creation of metadata and each has its own unique limitations that must be understood when creating course content. For example, when creating titles and headings in Microsoft Word, it is not enough to increase the font size and turn on a bold font style. In order for a screen reader to interpret a heading as such, the text of the heading must be created using the Styles feature. Microsoft Excel has a similar toolbar for inserting metadata into portions of a spreadsheet. Microsoft PowerPoint uses placeholders on its slide Layouts feature to ensure that files have correctly structured headings, lists, and proper reading order.

Just as in HTML, the use of tables within Microsoft Office files creates difficulties for screen readers. Unfortunately, these applications do not provide a means for associating cell contents with header information [19]. Nor do they provide a convenient way of including metadata summaries. Therefore, keeping tables simple is one way to increase accessibility. Another is to create a summary for each table you use and weave it into the text associated with the table. And, as mentioned above, checking the reading order with a screen reader is recommended.

Microsoft Word and PowerPoint are often used to create PDF files in Adobe Acrobat. When the original Microsoft files make use of the Styles feature mentioned above, the metadata automatically carries over to the resulting PDF file. For PDF files that have not been created in this way, a quick check will determine whether the text in a PDF file can be perceived by a screen reader: if you can perform a word search on a PDF file, the text is screen reader ready. If you cannot highlight individual words in a PDF file, that 
usually means that each page of the file is just an image. The situation can be corrected in Adobe Acrobat Pro by using the Optical Character Recognition feature and manually tagging titles and headings with the appropriate Adobe tags. Unlike the Microsoft Office applications, Adobe Acrobat Pro does have some functionality for associating table cell contents with header information. Like HTML, it uses tags that contain information about text and other elements within a file. As with HTML and the Microsoft applications, keeping tables simple and checking reading order with a screen reader are practices that will increase accessibility.

Both Microsoft Office and Adobe Acrobat Pro have built-in accessibility checkers that will yield accessibility compliance reports. HTML pages can also be subjected to an accessibility check by means of an application such as the Web Accessibility Evaluation [20] tool. Using these accessibility checkers is an excellent way to catch overlooked accessibility issues on a web page or within a supplemental file. However, as Bradbard and Peters [17] caution, "the true test of a Web site's accessibility should be undertaken by disabled students” (p. 38). Developers with only a superficial understanding of screen readers cannot be expected to have the thorough understanding of disabled user behavior that design and testing requires.

\section{Page Location Information}

Essentially, screen reading software presents page content as one long column of text. The visual cues offered by sidebars, bordered text boxes, and multiple text columns are not perceivable to screen readers. Be mindful that screen reading software may present page content and screen elements in a different reading order than the visual layout. Do not use spatial references like "top right" or "the navigation bar to your left” as the only way to identify content.

\section{CONCLUSION}

Collaborating with a legally blind screen reader user was an enlightening experience for our course development team. We grossly underestimated the time and skill needed to master screen reading software and developed tremendous respect for the patience required to access web-based materials through a synthesized voice. Although two of us had attended demonstrations of screen readers and even used screen reading software to read brief passages of on-screen content, it was not until we began collaborating with a skilled screen reader user that we realized the enormous difference between visually navigating a website and using a screen reader to do so. We began to understand what Chisholm and May [53] meant by "looking at the page through a straw" (p. 15). Ultimately, information design built on the behavior and experience of actual users is crucial to genuine accessibility. Perceivable content is just a minimum; truly accessible content should be designed to be fully navigable and understandable.

Our research questions focused on (1) course features that presented problems for a screen reader user and (2) recommendations to address these problems. We discovered that many accessibility issues could be addressed by providing uniform, predictable course layouts. Explaining the road map or structure of the course in the syllabus and putting material in consistent, logical places within the course were just as important as following the WCAG recommendations for accessible web pages. Additionally, we came to understand that, for particular areas within web pages and supplemental documents, the effective use of metadata can assist in organizing content, signaling important information, providing alternative explanations, and illuminating what otherwise might be confusing or even invisible.

We also came to realize that many of these design techniques can be implemented without the need for a particular set of advanced technical skills. The experience helped us to view course accessibility as an achievable goal and strengthened our commitment to provide inclusive materials for all students. It should be noted that our study focused on the experience of one screen reader user. We believe the study could and should be replicated with larger groups of students using screen readers to gain an even greater perspective from multiple users.

\section{REFERENCES}


1. Allen, I.E., Seaman, J., Lederman, D., and Jaschik, S. Conflicted: Faculty and Online Education, Babson Survey Research Group and Inside Higher Education (2012). http://www.insidehighered.com/sites/default/server files/survey/conflicted.html.

2. United States Department of Education. Report of the advisory commission on accessible instructional materials in postsecondary education for students with disabilities (2011). http://www2.ed.gov/about/bdscomm/list/aim/publications.html.

3. Coombs, N. Making Online Teaching Accessible: Inclusive Course Design for Students with Disabilities. San Francisco, CA: Jossey-Bass, 2010.

4. Burgstahler, S. The Development of Accessibility Indicators for Distance Learning Programs. ALT-J, Research in Learning Technology, 14(1), 79-102 (2006).

5. Nielsen, J. Designing Web Usability: The Practice of Simplicity. Indianapolis, IN: New Riders Publishing, 2000.

6. Opitz, C. Online Course Accessibility: A Call for Responsibility and Necessity. Educational Technology $\quad$ Review, $10 \quad 2002$. http://www.spiesforparents.cpd.usu.edu/DE\%20Resources/Ed\%20Tech\%20Review\%20\%20Accesibility\%20Issue.pdf.

7. Thatcher, J., Burks, M.R., Heilmann, C. Henry, S.L., Kirkpatrick, A., Lauke, P.H., Lawson, B., Regan, B., Rutter, R., Urban, M., and Waddell, C.D. Web Accessibility: Web Standards and Regulatory Compliance. Berkeley, CA: Apress Company, 2006.

8. Center for Universal Design. The Principles of Universal Design (2010). http://www.ncsu.edu/project/design-projects/udi/center-for-universal-design/the-principles-ofuniversal-design/.

9. WAI-ARIA. WAI-ARIA Overview (2012). http://www.w3.org/WAI/intro/aria.

10. WAI-ARIA Landmark Roles. Using WAI ARIA Landmark Roles-Updated (2010). http://www.paciellogroup.com/blog/2010/10/using-wai-aria-landmark-roles/.

11. Section 508.gov. Resources for understanding and implementing section 508. http://www.section508.gov/index.cfm.

12. Section 508 Standards Guide. Resources for understanding and implementing Section 508 (2010). http://www.section508.gov/index.cfm?fuseAction=stdsdoc.

13. Edmonds, C.D. Providing Access to Students with Disabilities in Online Distance Education: Legal and Technical Concerns for Higher Education. American Journal of Distance Education, 18(1), 5162 (2004).

14. W3C. World Wide Web Consortium (2012). http://www.w3.org/.

15. Web Accessibility Initiative. (2012). http://www.w3.org/WAI/.

16. WCAG 2.0. Web Content Accessibility Guidelines 2.0 (2012). http://www.w3.org/TR/WCAG20/.

17. Bradbard, D.A., and Peters, C. Web Accessibility Theory and Practice: An Introduction for University Faculty. The Journal of Educators Online, 7(1) (2010). http://www.thejeo.com/Archives/Volume7Number1/BradbardandPeterspaper.pdf.

18. Frey, B.A., and Kearns, L.R. Disability and Accessibility: Proactive Strategies to Improve Quality. In: K.I. Shattuck (Ed.), Assuring Quality in Online Education: Practices and Processes at Teaching, Resource, and Program Levels. Sterling, VA: Stylus Publishing, LLC., in press.

19. WebAIM. Web Accessibility in Mind (2012). http://webaim.org/.

20. WAVE. Web Accessibility Evaluation Tool (2012). http://wave.webaim.org/.

21. DO-IT. Disabilities, Opportunities, Internetworking, and Technology (2012). http://www.washington.edu/doit/.

22. Burgstahler, S. Universal Design of Instruction (UDI): Definition, Principles, Guidelines, and Examples (2012). http://www.washington.edu/doit/Brochures/Academics/instruction.html.

23. Burgstahler, S. Universal Design: Process, Principles, and Applications (2012). http://www.washington.edu/doit/Brochures/Programs/ud.html.

24. Burgstahler, S. Universal Design in Education: Principles and Applications (2012). http://www.washington.edu/doit/Brochures/Academics/ud edu.html. 
25. Scott, S.S., Mcguire, J.M., and Shaw, S.F. Universal Design for Instruction: A New Paradigm for Adult Instruction in Postsecondary Education. Remedial and Special Education, 24(6), 369-379 (2003).

26. Blackboard. http://www.blackboard.com/.

27. Moodle. https://moodle.org/.

28. Lewis, K., Yoder, D., Riley, E., So, Y., and Yusufali, S. Accessibility of Instructional Websites in Higher Education. EDUCAUSE Quarterly, 3, $29-35 \quad$ (2007). http://www.educause.edu/ero/article/accessibility-instructional-web-sites-higher-education.

29. Smith, J.A., and Lind, M.R. Website Accessibility for Users with Visual Impairment. Information Systems Education Journal, 8(53) (2010). http://isedj.org/8/53/.

30. Schmetzke, A. Online Distance Education-“Anytime, Anywhere” but Not for Everyone. Information Technology and Disabilities, 7 (2001). http://people.rit.edu/easi/itd/itdv07n2/axel.htm.

31. Kinash, S., Crichton, S., and Kim-Rupnow, W.S. A Review of the 2000-2003 Literature at the Intersection of Online Learning and Disability. American Journal of Distance Education, 18(1), 519 (2004).

32. Burgstahler, S., Corrigan, B., and McCarter, J. Making Distance Learning Courses Accessible to Students and Instructors with Disabilities: A Case Study. Internet and Higher Education, 7, 233246 (2004).

33. Frey, B.A., and King, D.K. Quality Matters ${ }^{\mathrm{TM}}$ Accessibility Survey: Institutional Practices and Policies for Online Courses (2011). ERIC Document Reproduction Service No. ED520903.

34. Frey, B.A., Kearns, L.R., and King, D.K. Template for an accessibility policy for online courses (2012). https://www.qualitymatters.org/accessibility-policy-request.

35. Quality Matters. (2010). http://www.qmprogram.org/.

36. Elias, T. Universal Instructional Design Principles for Moodle. International Review of Research in Open and Distance Learning, 11(2) (2010). http://www.irrodl.org/index.php/irrodl/article/view/869/1575\%29.

37. Duranczyk, I.M., and Higbee, J.L. Designing Distance Education for Access and Equity: Structure and Content. Proceedings of the 28th Annual Conference on Distance Teaching and Learning (2012). http://www.uwex.edu/disted/conference/Resource_library/proceedings/56421_2012.pdf.

38. Georgia Institute of Technology. Guidelines for Accessible Distance Education (2012). http://www.catea.gatech.edu/grade/guides/introduction.php.

39. Acrobat Accessibility Training Resources. http://www.adobe.com/accessibility/products/acrobat/training.html.

40. Accessibility in Microsoft office. http://www.microsoft.com/enable/products/office2010/default.aspx.

41. Lazar, J., Allen, A., Kleinman, J., and Malarkey, C. What Frustrates Screen Reader Users on the Web: A Study of 100 Blind Users. International Journal of Human-Computer Interaction, 22(3), 247-269 (2007).

42. Asakawa, C. What's the Web Like if You Can't See It? Proceedings of the 2005 International Cross-Disciplinary Workshop on Web Accessibility, 1-8, 2005.

43. Borodin, Y., Bigham, J.P., Dausch, G., and Ramakrishnan, I.V. More than Meets the Eye: A Survey of Screen-reader Browsing Strategies. Proceedings of the 2010 International Cross Disciplinary Conference on Web Accessibility (2010).

44. Leporini, B., and Buzzi, M. Learning by E-learning: Breaking Down Barriers and Creating Opportunities for the Visually-impaired. Lectures Notes in Computer Science, 4556, 687-696 (2007).

45. Muwanguzi, S., and Lin, L. Wrestling with Online Learning Technologies: Blind Students' Struggle to Achieve Academic Success. International Journal of Distance Education Technologies, 8(2), 43-57 (2010). 
46. Zebehazy, K.T. What Did that Alt Tag Say? Exploring Access to Visually-based Web Course Explanations. AER Journal: Research and Practice in Visual Impairment and Blindness, 2(2), 63-75 (2009).

47. Articulate. (2013). http://www.articulate.com/.

48. Adobe Captivate 6. (2013). http://www.adobe.com/products/captivate.html.

49. AccessAbility. Accessibility and Usability at Penn State Web (2012). http://accessibility.psu.edu/webpagetools.

50. VoiceThread. (2012). http://voicethread.com/.

51. Berners-Lee, T. Metadata Architecture (1997). http://www.w3.org/DesignIssues/Metadata.html.

52. Microsoft Office Support. (2012). http://office.microsoft.com/en-us/support/?CTT=97.

53. Chisholm, W., and May, M. Universal Design for Web Applications. Sebastopol, CA: O'Reilly Media, Inc., 2009.

\section{ABOUT THE AUTHORS}

Lorna R. Kearns is a senior instructional designer at the Center for Instructional Development and Distance Education at the University of Pittsburgh where she works with faculty to develop online courses. She is also a reviewer and trainer with Quality Matters, a non-profit organization that promotes quality in online courses.

Barbara A. Frey, D.Ed., is a senior instructional designer at the Center for Instructional Development and Distance Education at the University of Pittsburgh. In addition to her position at the University of Pittsburgh, Dr. Frey teaches as an instructor with the Online Teaching and Learning Program at the Colorado State University Global Campus. She is also a master reviewer and trainer with Quality Matters, a non-profit organization that promotes quality in online courses.

Gabriel McMorland is a disability services quality assurance assistant with the Disability Resources and Services office at the University of Pittsburgh. In his work, he creates accessible environments by understanding user behavior. 